\title{
The effect of nutrition on Asian and European pregnancies
}

\author{
J. G. BISSENDEN* \\ M.R.C.P. \\ P. H. ScOTT $\dagger$ \\ B.Sc. \\ B. A. WHARTON +
F.R.C.P.
}

\begin{abstract}
*Dudley Road Hospital, Birmingham 18; †Selly Oak Hospital, Birmingham 29, and $\ddagger$ Sorrento Maternity
Hospital, Birmingham 13
\end{abstract}

\begin{abstract}
Summary
An assessment of the nutritional status of Asian and European pregnant women was made using anthropometric and biochemical methods. Asian women, having normal pregnancies and appropriate for gestational age infants, had a higher plane of nutrition than did the corresponding European women. Asian women having light-for-gestational-age infants, by comparison with the normal Asian mothers, put on less fat in the second trimester of pregnancy and had some biochemical evidence of poorer nutrition.

It seems that poor nutrition during certain periods in Asian pregnancies can compromise fetal growth.
\end{abstract}

\section{Introduction}

The question of whether poor maternal nutrition compromises fetal growth is not new. Most evidence to say that it does is based on extreme circumstances such as wartime studies (Antonov, 1947) and the Dutch famine after the war (Smith, 1947). More recently, a large survey in Guatemala has shown that birth weight can be increased by supplementing the mother's diet during pregnancy; the carbohydrate fraction of the supplement seemed to be the more important (Lechtig et al.. 1975). It is possible that within Britain in the inner city conurbations, inadequate nutrition might create problems in the immigrant communities. In 2 studies on Asian communities in Leeds (Heckmatt et al., 1979) and London (Brook et al., 1980), it was shown that the vitamin D status of the pregnant Asian mothers was bordering on osteomalacia and this led to an increased incidence of hypocalcaemia in the infants. In the area of Birmingham served by Sorrento Maternity hospital, there is a large Asian population. Thirty-three per cent. of the mothers attending the ante-natal clinic were from the Asian sub-continent. Intakes of $<50 \mathrm{~g}$ of protein and $1500 \mathrm{cal} /$ day by the mothers have been recorded. Such was the setting for a prospective study comparing the nutrition of the Asian and European mothers and noting the effect on birth weight.

\section{Methods}

The methods used in this study were anthropometry and biochemistry. Mothers were followed either throughout pregnancy from an early booking visit or were taken into the study in later pregnancy when some form of pregnancy complication had developed, which may have compromised fetal growth. The complications were either bleeding at some stage in the pregnancy or hypertension.

Hypertension was defined as a diastolic blood pressure of more than $90 \mathrm{mmHg}$ at any time in the pregnancy outside labour. The mothers attended the ante-natal clinic at booking ( $<20$ weeks), 29 weeks, 33 weeks, and 37 weeks. Height was recorded at the booking visit and at this and all subsequent visits, weight, biceps, triceps and subscapular skin fold thicknesses (measured with Holtain calipers), and the mid upper arm circumference were measured. Incremental changes in these measurements per week between visits were calculated. Blood was taken on each occasion for estimation of plasma alkaline ribonuclease (RNase), which is raised in poor nutrition (Sigulem et al., 1973), transferrin which is lower, and the plasma valine : glycine ratio which is also lower in poor nutrition (Linblad, Rahintoole and Said, 1969). A 24-hr urine collected the day before attendance was analysed for nitrogen partition and hydroxyproline excretion, which are lower when growth is poor (Whitehead, 1965).

\section{Pregnancies producing normal infants}

As a first step, normal pregnancies producing appropriate-for-gestational age (AGA) infants were compared in the 2 races. Secondly, those pregnancies complicated by intrauterine growth failure, producing light-for-gestational age (LGA) infants were compared with the normal pregnancies within the same race. LGA was defined as an infant whose weight fell below the 10th centile for gestational age according to the data of Thomson, Billewicz and Hytten (1968), which take into account maternal height, sex of infant and parity of the mother. 


\section{Results}

Eleven Asian mothers having normal pregnancies and AGA infants were fatter at the booking visit than 28 corresponding European mothers. They remained fatter throughout pregnancy though not lighter. They were considerably shorter. Table 1

TABLE 1. Incremental changes per week in body measurements mean ( \pm s.e. mean) during the second trimester (i.e. from 9-20 weeks to 27-31 weeks)

\begin{tabular}{lccc}
\hline Measurement & European (28) & Asian (11) & Significance \\
\hline Weight (kg) & $0.42(0.03)$ & $0.42(0.04)$ & N.S. \\
Skin fold (mm): & & & \\
$\quad$ Triceps & $0.00(0.03)$ & $0.22(0.03)$ & $P<0.001$ \\
$\quad$ Biceps & $0.10(0.02)$ & $0.21(0.07)$ & $P<0.05$ \\
$\quad$ Subscapular & $0.15(0.04)$ & $0.25(0.07)$ & $P \bumpeq 0.07$ \\
Mid upper arm & & & \\
$\quad$ muscle & & & \\
circumference & $0.03(0.01)$ & $-0.01(0.02)$ & N.S. \\
(mm) & $0.03(0.01$ \\
\hline
\end{tabular}

shows the incremental changes per week in the 2 nd trimester. The Asian women gained fat more rapidly (higher skin fold increments) but weight and mid upper arm circumference gain were comparable in the 2 groups.

The main biochemical differences in the 2 races were also in the second trimester of pregnancy. At the 29-week visit, compared to the European mothers, the Asian mothers had a lower plasma RNase activity, a higher concentration of plasma transferrin and a higher plasma valine : glycine ratio. Figure 1 shows the individual values with means and standard errors of plasma transferrin plotted against plasma alkaline RNase in the 2 races.

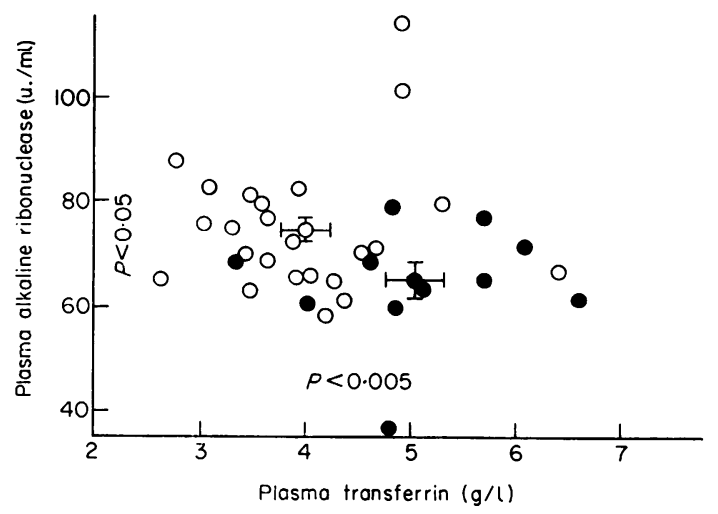

FIG. 1. Values of plasma alkaline ribonuclease plotted against plasma transferrin values at 29 weeks of pregnancy in Asian and European women having normal pregnancies and appropriate-for-gestational-age infants. Collective results expressed as mean and s.e. mean. $O$, normal European pregnancy; 0 , normal Asian pregnancy (29 weeks).
There were no differences in the urinary nitrogex partition or the excretion of hydroxyproline at this stage of pregnancy.

It seemed then, that Asian women who achieve $\overrightarrow{\overline{\vec{b}}}$ the same standard of intrauterine growth as the European women were shorter, fatter and put oo more fat than the Europeans. In addition to these anthropometric differences, the Asian women at the same stage of pregnancy had some biochemicato evidence of a higher nutritional plane.

II Pregnancies associated with intrauterine growth

In this part of the study, 17 Europeans and 18 Asians were followed from early pregnancy whereas. 14 Europeans and 23 Asians were taken on after ther 20th week of pregnancy. The same anthropometrig and biochemical measurements were made at the standardized times of pregnancy. Three groups of patients emerged: group I, cryptogenic intrauterinev growth failure, where there was no apparent cause for the LGA infant; group II, a complicatedpregnancy but normal intrauterine growth; anp group III, complicated pregnancy resulting in poof intrauterine growth and a LGA infant. These groups 3 in their turn were compared with the 39 totâty normal subjects who formed the first part of tie study.

\section{Results}

Figure 2 shows the weight and triceps skin fold thicknesses at each visit during pregnancy comparing all LGA infants (groups I and III) with the norma mothers. Asian women who had LGA infants put on less fat particularly in the second trimester so that in $\overrightarrow{\vec{b}}$ later pregnancy they were thinner than the normaB Asian women. In contrast, European mothers who had LGA infants were heavier at booking and remained so throughout pregnancy but their rate of weight and fat gain were very similar to the norma?. European pregnancies.

The biochemistry results were unconvincing because of the subdivision of the patients into the? small groups. Compared to normal, Asian women with cryptogenic intrauterine growth failure had at some stage in their pregnancy a raised plasmax RNase activity and a reduced valine : glycine ratio These results were not found in the European women. The effect of the pregnancy complications (e.g. hypertension) was to slant the biochemistry in the direction of results associated with poor nutritionw in both races.

\section{Discussion}

The anthropometric data distinguished the races ${ }^{\text {? }}$ in the study of intrauterine growth failure. Asian women with cryptogenic intrauterine growth failure $\frac{\vec{\Phi}}{\mathbb{D}}$

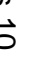




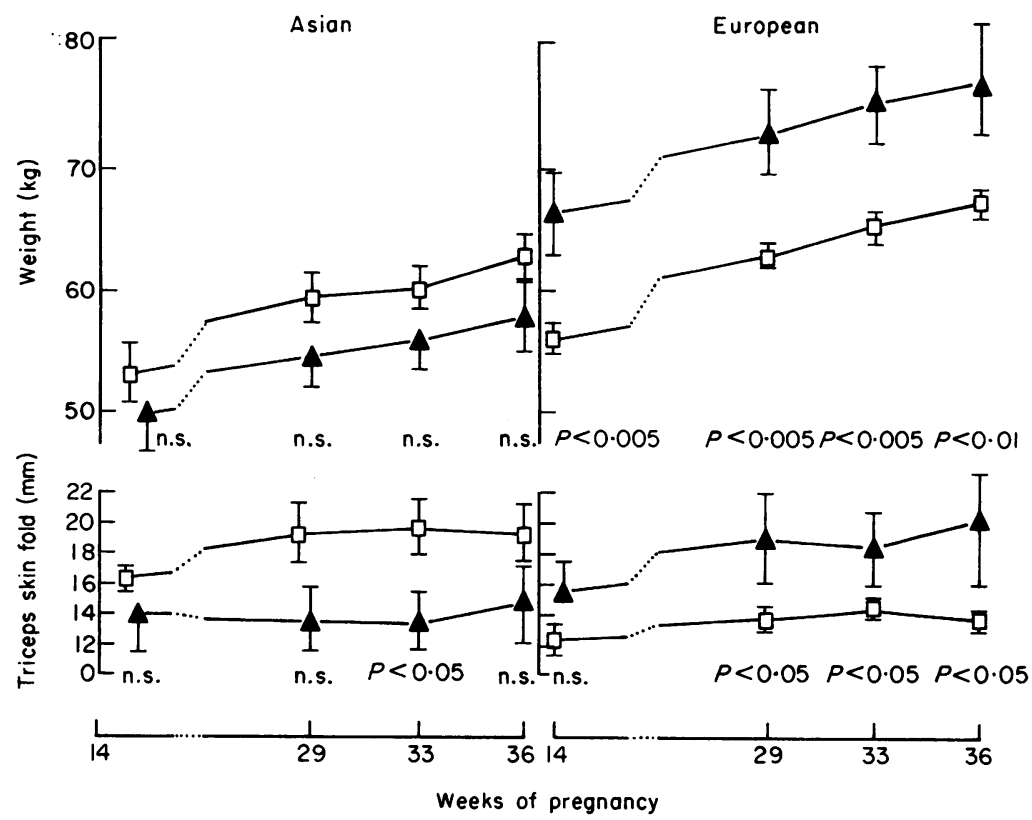

FIG. 2. Weight and triceps skin fold thicknesses (mean and s.e. mean) in mothers followed-up from booking to delivery (28 Europeans and 11 Asians) and in those producing a light-for-gestational-age (LGA) (8 Europeans and 5 Asians). $\square$, normal pregnancy (AGA infant). $\Delta$, growth retarded pregnancy (LGA infant).

put on less weight and fat in the second trimester. Of the 15 Asian women having LGA infants, 12 had uncomplicated pregnancies. In contrast, of the 9 European women having LGA infants, only one pregnancy was uncomplicated. In the complicated pregnancies, the women were heavier and fatter than normal. The biochemical data were partially supportive in that values of plasma RNase and valine : glycine ratios linked with a poorer nutritional status were found in the Asian women whose pregnancies were associated with poor intrauterine growth.

What then is the significance of these results? The first part of the study suggests that if Asian mothers are particularly well nourished, they can achieve a standard of intrauterine growth comparable to the European. The second part of the study, however, suggests that if the diet is poor, intrauterine growth may be compromised. These results would support a trial of food supplementation of at risk Asian mothers. Such a trial is in progress.

\section{References}

Antonov, A.N. (1947) Children born during the siege of Leningrad in 1942. Journal of Pediatrics, 30, 250.
Brooke, O.G., Brown, I.R.F., Bone, C.D.M. CARTER, N.D., Cleeve, H.J.W., MaXWell, J.D., Robinson, V.P. \& WINDER, S.W. (1980) Vitamin D supplements in pregnant Asian women: effects on calcium status and fetal growth. British Medical Journal, 1, 751.

Heckmatt, J.Z., Peacock, M., Davies, A.E.J. \& Isherwood, D.M. (1979) Plasma 25-hydroxyvitamin $D$ in pregnant Asian women and their babies. Lancet, ii, 546.

Lechtig, A., Delgado, H., Lasky, R., Yarbrough, C., KleIN, R.E., HABICHT, J-P. \& BehaR, M. (1975) Maternal nutrition and fetal growth in developing countries. American Journal of Diseases of Children, 129, 553.

Linblad, B.S., Rahintoole, R.J. \& SAID, M. (1969) The venous plasma free aminoacid levels of mother and child during delivery: (III) in a lower socio-economic group of a refugee area in Karachi, West Pakistan, with special reference to the small for dates syndrome. Acta paediatrica scandinavica, 58, 497.

Sigulem, D.M., Brasel, J.A., Velasco, E.G., Rosso, P. \& WinicK, M. (1973) Plasma and urine ribonuclease as a measure of nutritional status in children. American Journal of Clinical Nutrition, 26, 793.

SMITH, C.A. (1947) The effect of wartime starvation in Holland upon pregnancy and its product. American Journal of Obstetrics and Gynecology, 53, 599.

Thomson, A.M., Billewicz, W.Z. \& Hytten, F.E. (1968) The assessment of fetal growth. Journal of Obstetrics and Gynaecology of the British Commonwealth, 75, 906.

WHITEHEAD, R.G. (1965) Rapid determination of some plasma amino-acids in subslinical kwashiorkor. Lancet, ii, 567. 